\title{
Modification of niobium surfaces using plasma electrolytic oxidation in silicate solutions
}

\author{
Maciej Sowa • Alicja Kazek-Kęsik • \\ Agnieszka Krząkała • Robert P. Socha • Grzegorz Dercz • \\ Joanna Michalska • Wojciech Simka
}

Received: 31 October 2013 /Revised: 20 November 2013 /Accepted: 22 November 2013 /Published online: 11 December 2013

(C) The Author(s) 2013. This article is published with open access at Springerlink.com

\begin{abstract}
Herein, a study of the plasma electrolytic oxidation (PEO) of niobium in an anodising bath composed of potassium silicate $\left(\mathrm{K}_{2} \mathrm{SiO}_{3}\right)$ and potassium hydroxide $(\mathrm{KOH})$ is reported. The effects of the $\mathrm{K}_{2} \mathrm{SiO}_{3}$ concentration in the bath and the process voltage on the characteristics of the obtained oxide layers were assessed. Compact, barrier-type oxide layers were obtained when the process voltage did not exceed the breakdown potential of the oxide layer. When this threshold was breached, the morphology of the oxide layer changed markedly, which is typical of PEO. A significant amount of silicon, in the form of amorphous silica, was incorporated into the oxide coatings under these conditions compared with the amount obtained with conventional anodising. This surface modification technique led to an improvement in the corrosion resistance of niobium in Ringer's solution, regardless of the imposed process conditions.
\end{abstract}

Keywords Niobium · Plasma electrolytic oxidation · Corrosion resistance $\cdot$ Silicate solutions

\footnotetext{
M. Sowa • A. Kazek-Kęsik • A. Krząkała • W. Simka ( $₫)$ Faculty of Chemistry, Silesian University of Technology, B. Krzywoustego Street 6, 44-100 Gliwice, Poland e-mail: wojciech.simka@polsl.pl

R. P. Socha

Jerzy Haber Institute of Catalysis and Surface Chemistry PAS, Niezapominajek Street 8, 30-239 Krakow, Poland

G. Dercz

Institute of Materials Science, University of Silesia, 75 Pułku Piechoty Street 1 A, 41-500 Chorzów, Poland

J. Michalska

Faculty of Materials Engineering and Metallurgy, Silesian University of Technology, Krasińskiego Street 8, 40-019 Katowice, Poland
}

\section{Introduction}

The field of biomaterials is concerned with the development of a range of novel materials that are capable of substituting for or enhancing malfunctioning organs or their components. This goal can be achieved by either the invention of entirely new substances or the combination of substances with a set of unique properties and the modification of pre-existing materials. Biomaterials that are intended to be implanted subcutaneously are expected to fulfil a collection of prerequisites that depend on the destination of the material in question $[1,2]$. Metallic biomaterials are primarily used for orthopaedic implants, such as devices for reconstructive knee or hip surgeries. Thus, these materials need to possess adequate load-bearing properties, corrosion resistance and biocompatibility [3].

The main representative groups of the metallic biomaterials are stainless steels (SS), Co-Cr alloys, Ti and its alloys. The mechanical strength of the first two is superior to that of Ti. Unfortunately, the release of the toxic metal ions upon exposure to corrosive body fluids has limited their widespread application [4]. Although titanium and its alloys are not completely resistant to corrosion under physiological conditions, an increase in the concentration of Ti ions in the human body does not induce any severe immunological response. This lack of activity is mainly due to the high reactivity of titanium ions towards water molecules and other anionic species present in the human body, which leads to the formation of stable hydroxides and salts of the element. In contrast, the components of $\mathrm{Co}-\mathrm{Cr}$ alloys and stainless steels may cause various immunological responses; for example, nickel and chromium may form ions that are stable under physiological conditions and might combine with biomolecules, leading to toxic reactions [5]. Additionally, the corrosion of metallic implants diminishes their mechanical strength, especially after prolonged exposure to the corrosive environment [6]. 
Amongst the excellent properties of titanium alloys [7, $8]$ are their light weight, exceptional corrosion resistance, great biocompatibility and good strength-to-weight ratio. One of the most distinguished representatives of this group for biomedical use is the $\alpha+\beta$ phase Ti-6Al-4V alloy, although it was originally designed to be used in the aerospace industry. Nevertheless, there is a tendency to replace this material on account of reports of the cytotoxic properties of vanadium [9-12]. Aluminium has been characterised as a neurotoxin, and its presence in humans may possibly be associated with the senile dementia of Alzheimer type [13-15]. Furthermore, the wear resistance of Ti-6Al-4V alloy is low. Therefore, when it is used in joint prostheses, the build-up of debris is inevitable, which leads to an inflammatory response $[16,17]$. In order to preserve the beneficial properties of the Ti-6Al-4V alloy and alleviate the harmful effects caused by vanadium and aluminium, these components can be substituted with other $\alpha$ - and $\beta$-stabilising elements, such as niobium, tantalum and zirconium, which are biocompatible [11, 17-26].

Similar to titanium, niobium is a member of the valve metals group, which means that it is able to spontaneously grow compact, barrier-type oxide layer that tightly covers the entire surface of the metal, preventing further chemical attack [27]. The high biocompatibility of these metals stems from this feature [15]. According to Eisenbarth et al. [17], niobium is amongst the most biocompatible $\beta$-stabilising elements, as determined from experiments on MC3T3-E1 and GM7373 cells. Additionally, it was found that Ti alloys containing $\mathrm{Nb}$, $\mathrm{Ta}$, and $\mathrm{Zr}$ have improved corrosion performance compared with commercially pure (CP) titanium and Ti-6Al-4V alloy $[19,21,22]$.

A lack of response by the organism receiving the metal implant is considered beneficial. However, because bioinert materials tend to be encapsulated in fibrous tissue after implantation, some sort of mechanical fixation is necessary to ensure the stability of the device. This step can be omitted when the surface of the implant is bioactive, which means that it can actively form a permanent fixation with treated bone $[28,29]$. To accomplish this goal, a wide variety of surface modification methods have been developed [29], including plasma spraying [30], glow discharge plasma treatment [31], ion implantation/deposition [32], physical vapour deposition, chemical vapour deposition, alkali treatment [33, 34], sol-gel coatings [35] and electrochemical methods.

Anodic oxidation presents a relatively cheap and simple method for the surface treatment of valve metals. The goal of this processing technique is to thicken the naturally occurring passive metal oxide layer using the flow of electric current through a standard electrolytic system composed of an anode (the workpiece), cathode, electrolysis cell filled with an electrolyte solution and a power supply $[20,27,29,30]$. In general, anodic oxidation can be conducted under two distinct conditions. The first is conventional anodising, which leads to the growth of a relatively thin, compact, barrier-type oxide layer. It is performed by increasing the process voltage which does not exceed the breakdown potential of the oxide layer. The second method is accomplished by applying a voltage that exceeds this threshold. This method is commonly referred to as plasma electrolytic oxidation (PEO) or micro-arc oxidation [36]. Under these conditions, numerous sparks can be observed over the treated workpiece, and oxide generation, oxide dissolution, and oxygen evolution occur concurrently [37]. Temperatures of several thousand degrees Celsius can be attained in the vicinity of the sparks. This phenomenon, coupled with the rapid cooling provided by the circulating electrolyte, results in the formation of unique phases within the oxide layer. The strong electric fields present in the spark zones contribute to the migration of electrolyte ions towards the metal surface. Subsequently, solvent evaporation and electrolyte components crystallisation lead to the eventual incorporation of the ionic species present in the anodising bath into the oxide layer formed onto the workpiece. PEO can be used to obtain oxide layers that are up to several hundred micrometer thick with a large number of open and closed pores.

Silicon is believed to have a large impact on the structure and mechanical properties of connective tissue because of its contribution in the biomineralisation process, where the presence of orthosilicic acid $\left(\mathrm{Si}(\mathrm{OH})_{4}\right)$ leads to hydroxyapatite (HA) precipitation. Additionally, collagen proliferation and the differentiation and synthesis of osteoblasts are affected by the Si content in the organism. Silicon deficiency diminishes the growth rate of young mammals $[2,38]$. The effects of the silica content in calcium phosphate bioceramics was investigated by Ning et al. [39]. Neonatal rat calvaria osteoblasts were used for in vitro studies. Increasing the Si content in the investigated $\mathrm{CaP}-\mathrm{SiO}_{2}$ bioceramics (up to $80 \%$ by weight) resulted in higher concentrations of proteins and higher alkaline phosphatase specific activity. Dorozkhin [40] studied how the incorporation of silica into the $\mathrm{CaP}$ bioceramics affected the process of biomineralisation in revised simulated body fluid (r-SBF). The investigated composite was composed of 60-65\% silicon-stabilised alpha tricalcium phosphate $(\alpha$ TCP), 30-35 \% HA and balance Si, by weight. The entire surface of the specimen was found to be covered by a $0.8-\mu \mathrm{m}$ thick HA precipitate after exposure to r-SBF.

In this study, the process of direct current plasma electrolytic oxidation of pure niobium in solutions that contained potassium silicate and potassium hydroxide was investigated. The oxide coatings resulting from this treatment were analysed in terms of their surface morphology, chemical composition, phase composition, and corrosion resistance in Ringer's solution. The voltage-time responses were recorded during treatment concurrently with real-time imaging of the surface of the workpiece. 


\section{Materials and methods}

Pure niobium samples (BIMO Metals, Wrocław, Poland) were obtained by cutting the metal sheet into $10 \times 10 \times 1-\mathrm{mm}$ fragments. Then, the samples were subjected to chemical etching in an $\mathrm{HF}\left(1 \mathrm{~mol} \mathrm{dm}^{-3}\right)$ and $\mathrm{H}_{2} \mathrm{SO}_{4}\left(4 \mathrm{~mol} \mathrm{dm}^{-3}\right)$ solution for $2 \mathrm{~min}$, rinsed with distilled water and cleaned ultrasonically for 5 min in 2-propanol and deionised water (sample - Etched Nb).

Pretreated samples were anodised in an electrolyte solution of potassium silicate $\left(\mathrm{K}_{2} \mathrm{SiO}_{3} ; 0.1,0.5\right.$, and $\left.1.0 \mathrm{~mol} \mathrm{dm}^{-3}\right)$ and potassium hydroxide $\left(\mathrm{KOH} ; 5 \mathrm{~g} \mathrm{dm}^{-3}\right)$. The process was carried out galvanostatically with a current density of $0.1 \mathrm{~A}$ $\mathrm{dm}^{-2}$ up to a voltage of 100,200 , or $400 \mathrm{~V}$ for 10 min using a DC power supply (PWR800H, Kikusui, Japan). The sample designations and their corresponding operational conditions are collated in Table 1. After anodising, the samples were rinsed with distilled water and cleaned in an ultrasonic bath with 2-propanol and deionised water. A titanium plate served as the cathode. The electrolysis cell was cooled externally by circulating water to absorb the process heat. The apparatus was equipped with a magnetic stirrer to minimise the concentration gradients within the solution. The surface of the workpiece during the anodising was monitored using a commercial digital camera (Sony DSC-W30).

A scanning electron microscope (SEM, Hitachi S-3400N, accelerating voltage $=25 \mathrm{kV}$ ) was used for characterisation of the surface morphology of the anodised samples. Both planar and cross-sectional views of the specimens were captured. The chemical compositions of the observed images were determined using an energy-dispersive X-ray spectrometer (EDX, Thermo Noran) paired with the SEM.

A Mitutoyo Surftest SJ-301 profilometer was used to measure the surface profiles and Ra parameters of the samples according to ISO4287:1997. Calculation of the Ra parameter was accomplished according to Eq. (1), which is the arithmetic mean of the sum of the surface profiles for a given sample.

$\mathrm{Ra}=\frac{1}{l} \int_{0}^{l}|Z(x)| d x$,

where $|Z(x)|$ is the absolute ordinate value inside the elementary measuring length and $l$ is the elementary length in the $x$ direction (average line) used to determine the ruggedness of the surface profile.

A drop shape analysis system (DSA 10Mk2, KRÜSS) was employed for the determination of the contact angles of the niobium specimens. An image analysis system (DSA software) calculated the contact angle from the shape of the drop that was recorded using a video camera. Ultra-high-purity water $(0.20 \mu \mathrm{L})$ was used at room temperature. Ten drops were analysed for each sample.

An X-Pert Philips PW 3040/60 diffractometer working at $30 \mathrm{~mA}$ and $40 \mathrm{kV}$, which was equipped with a vertical goniometer and an Eulerian cradle, was used for the XRD experiments. The wavelength of the radiation $(\lambda \mathrm{CuK} \alpha)$ was $1.54178 \AA$. Grazing incidence X-ray diffraction (GIXD) patterns were recorded in a $2 \theta$ range from $10^{\circ}$ to $80^{\circ}$ with a $0.05^{\circ}$ step for the incident angle $\alpha=0.25^{\circ}$.

X-ray photoelectron spectroscopy (XPS) has been used to determine the atomic composition and the electronic states of elements at the analysed surface. The XPS measurements were performed in an ultrahigh vacuum $\left(9 \times 10^{-10} \mathrm{mbar}\right)$ system equipped with a hemispherical analyser (SES R 4000, Gammadata Scienta). An unmonochromatised Al $\mathrm{K} \alpha \mathrm{X}$-ray source of incident energy of $1486.6 \mathrm{eV}$ was applied to generate core excitations. The energy resolution of the system, measured as a full width at half maximum for an $\mathrm{Ag} 3 d_{5 / 2}$ excitation line, was $1.0 \mathrm{eV}$ The energy scale of the analyser was calibrated according to ISO 15472:2001 and the energy scale of the acquired spectra were calibrated for maximum of $\mathrm{C} 1 \mathrm{~s}$ core excitation at electron binding energy (BE) of $285 \mathrm{eV}$. The analytical depth for the measured samples (approximated as an $\mathrm{SiO}_{2}$ layer) was $11.9 \mathrm{~nm}$ as calculated for an excitation of energy $1487 \mathrm{eV}$.

The extent to which the niobium samples were resistant to corrosion in Ringer's physiological solution $\left(8.6 \mathrm{~g} \mathrm{dm}^{-3}\right.$ $\mathrm{NaCl}, 0.3 \mathrm{~g} \mathrm{dm}^{-3} \mathrm{KCl}$, and $0.48 \mathrm{~g} \mathrm{dm}^{-3} \mathrm{CaCl}_{2} \cdot 6 \mathrm{H}_{2} \mathrm{O}$ (Baxter, USA)) was recorded. The system employed for the analysis consisted of a standard two-chamber electrolysis cell that was equipped with three electrodes. The sample served as the working electrode. A saturated calomel electrode (SCE) with a Haber-Luggin capillary was used as the reference electrode. The auxiliary electrode was chosen to be a platinum mesh. A PARSTAT 4000 potentiostat powered the experiments, and it
Table 1 The sample labels, treatment condition, $\mathrm{Nb} / \mathrm{Si}$ surface atomic ratios, roughnesses, layer thicknesses, and contact angles of the sample surfaces; $\mathrm{KOH}-5 \mathrm{~g} \mathrm{dm}^{-3}$

\begin{tabular}{ccccc}
\hline Sample & $\mathrm{Nb} / \mathrm{Si}$ surface atomic ratio & $\mathrm{Ra}, \mu \mathrm{m}$ & Thickness, $\mu \mathrm{m}$ & Contact angle, deg \\
\hline Etched $\mathrm{Nb}$ & - & 0.28 & - & $104.4 \pm 6.18$ \\
Nb-ANO-0.5-100 & 9.31 & 0.28 & $1.11-1.63$ & $80.30 \pm 7.10$ \\
Nb-ANO-0.5-200 & 3.56 & 0.38 & $1.15-1.71$ & $47.90 \pm 9.45$ \\
Nb-ANO-0.5-400 & 0.67 & 1.85 & $16.1-22.2$ & Highly hydrophilic \\
Nb-ANO-0.1-400 & 2.75 & 0.82 & $16.1-21.4$ & Highly hydrophilic \\
Nb-ANO-1.0-400 & 0.04 & 3.57 & $21.4-43.3$ & Highly hydrophilic \\
\hline
\end{tabular}


Fig. 1 The voltage-time progression for the niobium samples anodised at $400 \mathrm{~V}$ in solutions with different concentrations of $\mathrm{K}_{2} \mathrm{SiO}_{3}$ (Nb-ANO- $x-400$ samples)

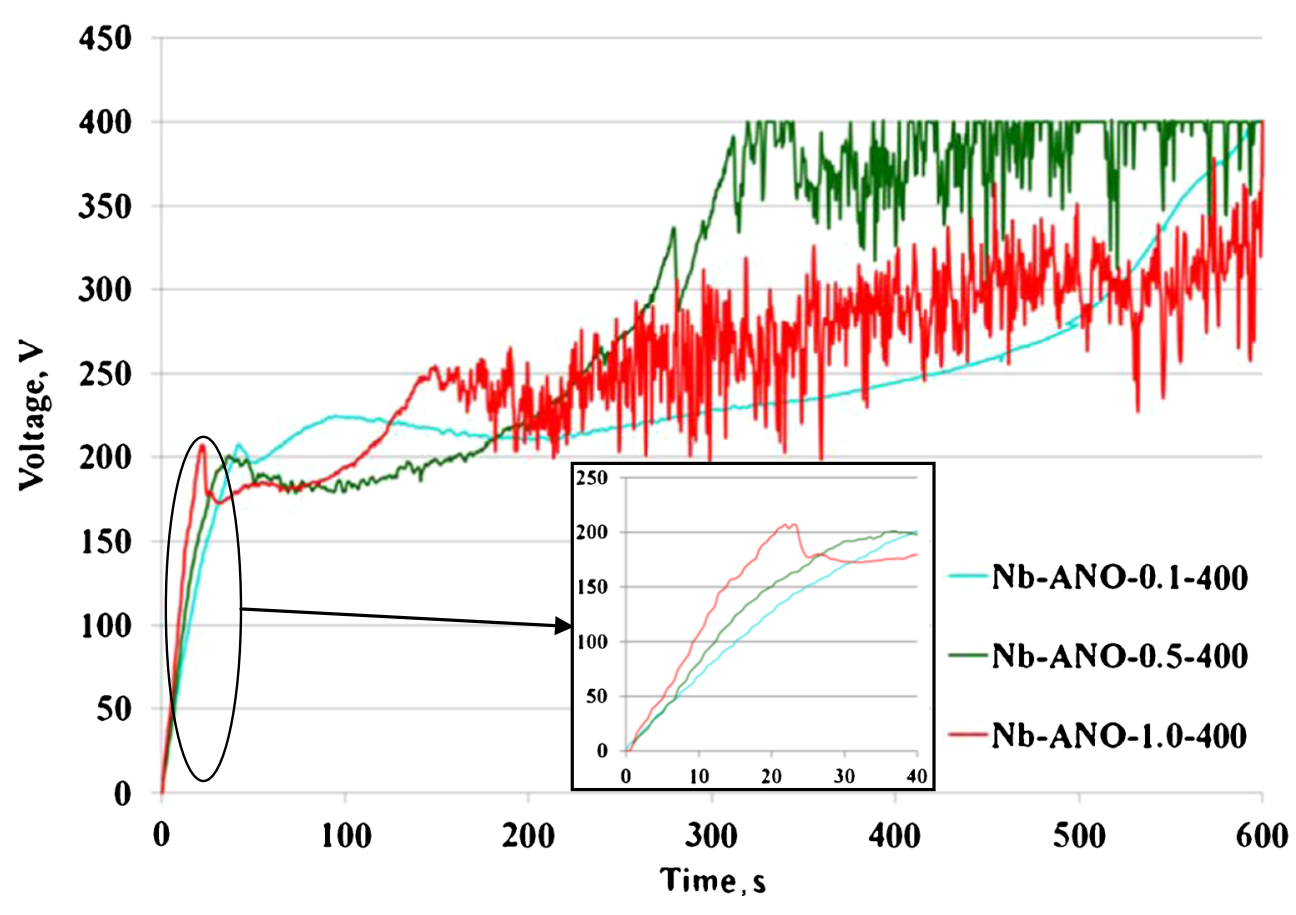

was controlled using Versa Studio software. The investigations comprised the following set of measurements: (a) open-circuit potentials were recorded with time $\left(E_{\mathrm{OCP}}=f(t)\right)$, (b) the $\log$ $i=f(E)$ relationships in the potential range of $E_{\mathrm{OCP}}-20 \mathrm{mV}$ to $E_{\mathrm{OCP}}+70 \mathrm{mV}\left(\mathrm{d} E \mathrm{~d} t^{-1}=1 \mathrm{mV} \mathrm{s}^{-1}\right)$ were evaluated and (c) the cyclic polarisation curves $(\mathrm{CV})$ in the potential range from $E_{\mathrm{OCP}}-0.1 \mathrm{~V}$ to $3 \mathrm{~V}\left(\mathrm{~d} E \mathrm{~d} t^{-1}=10 \mathrm{mV} \mathrm{s}^{-1}\right)$ were determined.

All solutions were prepared using analytical grade reagents that were manufactured by POCh Gliwice, Poland. Deionised water was obtained from a Millipore Milli-Q system.
Fig. 2 Real-time images of the surfaces of the niobium samples subjected to plasma electrolytic oxidation; the size of the depicted regions is $0.63 \mathrm{~cm}^{2}$; sparks are encircled for the sake of clarity
Nb-ANO-0.1-400 sample

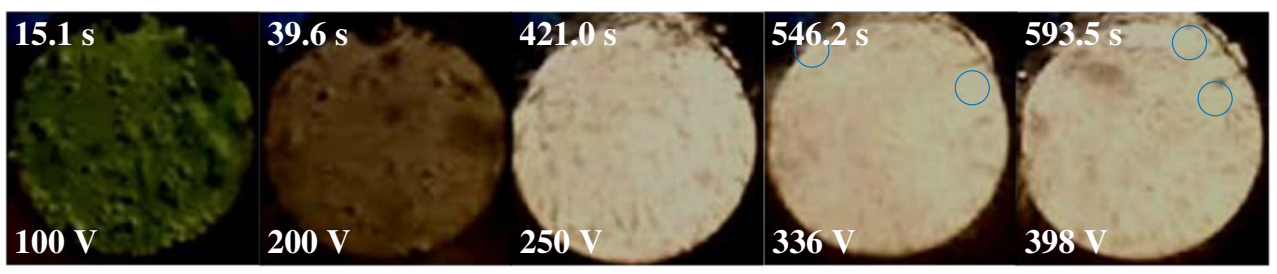

Nb-ANO-0.5-400 sample

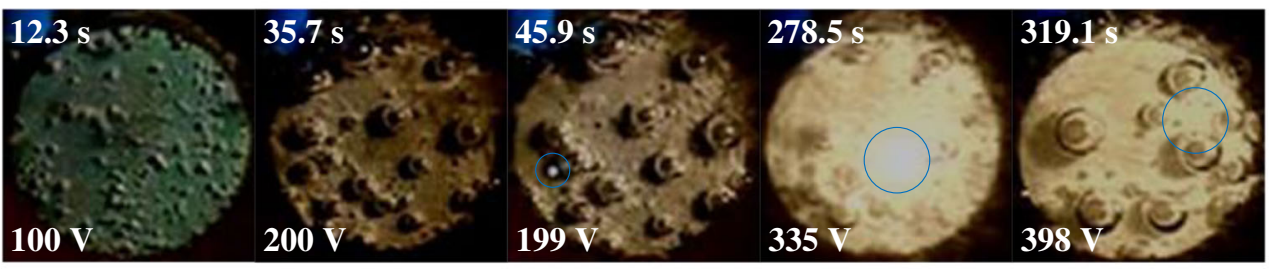

Nb-ANO-1.0-400 sample

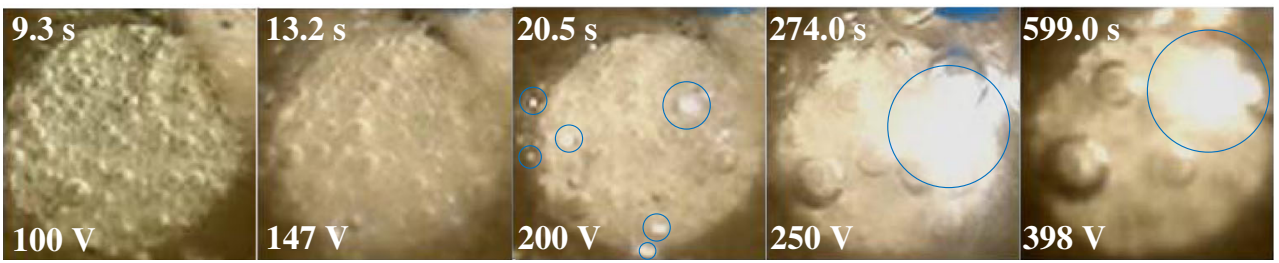




\section{Results and discussion}

The voltage-time responses recorded during the process of plasma electrolytic oxidation of the niobium samples anodised at $400 \mathrm{~V}$ in solutions that contained $0.1,0.5$, and $1.0 \mathrm{~mol} \mathrm{dm}^{-3}$ of $\mathrm{K}_{2} \mathrm{SiO}_{3}$ are presented in Fig. 1. Three different regions can be identified in the diagram. Similar findings have been reported by others [20, 37, 41-44] for the PEO of other valve metals or their alloys. At first, the voltage rapidly and linearly increased, which is typical for a conventional anodising process. The second region, where the rate at which the voltage is increasing decreases, corresponds to a decrease in the rate at which the oxide layer is thickening. In the last region of the voltage-time curves, the evolution of oxygen became very intense, and micro-discharges began to appear uniformly on the treated surface. At first, the sparks were bluish-white, small in diameter and great in number. As the time of treatment increased, the number of the sparks decreased, and their diameter decreased [36]. This effect occurs because as the anodic oxide film increases in the thickness, more energy is needed for an electric current to pass through it. Thus, the discharges became localised at the sites where the oxide layer was relatively thin [43]. The voltage increments in the first region were dependent on the concentration of potassium silicate, and these were equal to $6.1,7.3$, and 10.1 for 0.1 , 0.5 , and $1.0 \mathrm{~mol} \mathrm{dm}^{-3}$ of $\mathrm{K}_{2} \mathrm{SiO}_{3}$, respectively, in the range of voltages of approximately $0-200 \mathrm{~V}$ (Fig. 1). Less linear character in the curves can be observed in the second region of the $U-t$ curves. The average rates of the voltage increase in this region were 1.3, 1.6, and 1.9 for $0.1,0.5$, and $1.0 \mathrm{~mol} \mathrm{dm}^{-3}$ of $\mathrm{K}_{2} \mathrm{SiO}_{3}$, respectively. Once the process voltage reached a value of 250-300 V, the last region could be reached, where large oscillations in the $U$ - $t$ diagram can be observed (Fig. 1). These are associated with the vigorous evolution of oxygen and the sparking phenomena.

The surfaces of the treated niobium samples at various stages of the plasma electrolytic oxidation are depicted in Fig. 2. The colours of the samples were continuously changing with the increasing voltage up to approximately 200-250 V. After the treatment, the surfaces of the samples appeared to be white. Gas bubbles could be observed from the very first moments of the treatment. In the case of the niobium sample that was anodised in the least concentrated potassium silicate solution $\left(0.1 \mathrm{~mol} \mathrm{dm}^{-3}\right)$, larger sparks could be observed after
Fig. 3 SEM images of the surface morphologies of the etched niobium and the niobium that was anodised under various conditions (Nb-ANO- $x-y$ samples)
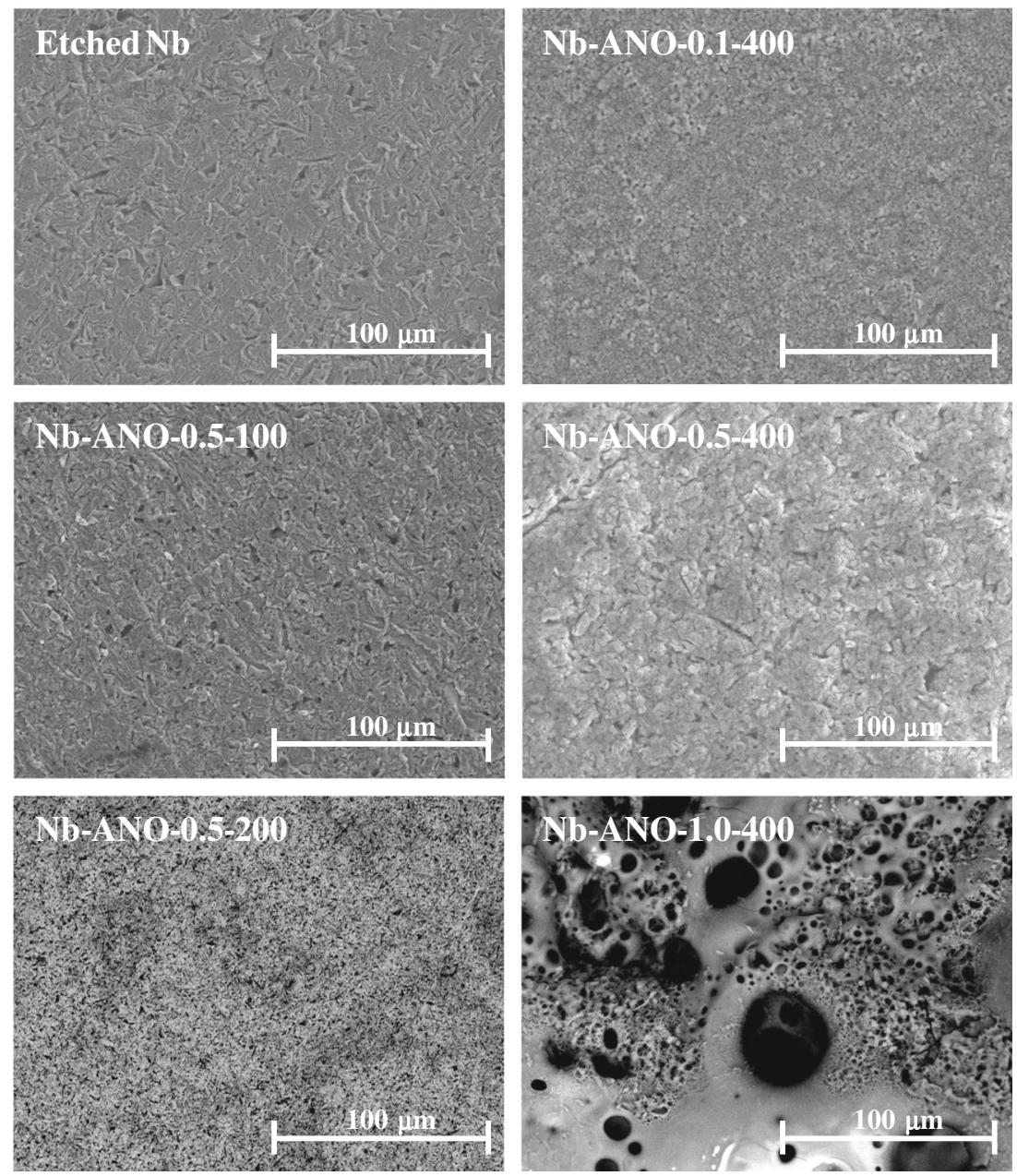
reaching a voltage of $336 \mathrm{~V}$. The intensity of the sparking was found to be the least intense for this sample (Fig. 2). For the Nb-ANO-0.5-400 sample, it was found that the bubble density increased relative to the Nb-ANO-0.1-400 sample. First, singular sparks could be observed on this sample at approximately $200 \mathrm{~V}$. Intense micro-discharges with large diameters were identified once a voltage of $300 \mathrm{~V}$ was attained, which is also reflected in the shape of the $U-t$ curve for this sample (Fig. 1). The most intense evolution of gas bubbles and sparking was found at the surface of the sample anodised in the solution that contained $1.0 \mathrm{~mol} \mathrm{dm}^{-3}$ of $\mathrm{K}_{2} \mathrm{SiO}_{3}$ (Fig. 2). The first discharges could be observed on this sample once the process voltage reached a value of $200 \mathrm{~V}$, which was also associated with a decrease in the bubble density. Shortly afterwards, very energetic sparks appeared on the surface.

SEM images of the pretreated (etched) and anodised niobium metal samples are shown in Fig. 3. The surface morphology of the niobium sample that underwent the etching procedure is typical of this type of treatment. The surface is rather smooth (Table 1, Fig. 4), with an Ra equal to $0.28 \mu \mathrm{m}$. The contact angle tests proved that the pretreated niobium surface is hydrophobic (Table 1). Anodising at a voltage equal to $100 \mathrm{~V}$ in a $0.5 \mathrm{~mol} \mathrm{dm}^{-3} \mathrm{~K}_{2} \mathrm{SiO}_{3}$ solution resulted in the generation of a relatively thin oxide layer (Table 1, Fig. 5) with a roughness similar to that of the pretreated niobium (Table 1, Fig. 4). It is characteristic of the conventional anodic oxidation that the morphology of the coatings grown on the metal surface is reminiscent of that of the bare metal (Fig. 3) [45]. Anodising also led to an increase in the hydrophilic character of the metal surface due to the formation of the oxide layer, as can be observed from the contact angle measurements (Table 1, Fig. 4). A small amount of $\mathrm{Si}$ was shown to be incorporated into the oxide layer, as determined from the EDX tests (Table 1, Fig. 5). Increasing the treatment voltage up to $200 \mathrm{~V}$ and keeping the $\mathrm{K}_{2} \mathrm{SiO}_{3}$ concentration at $0.5 \mathrm{~mol} \mathrm{dm}{ }^{-3}$ resulted in a minor increase in the surface roughness (Table 1, Fig. 4). However, the surface morphology of the layer was not altered by a large factor (Fig. 3), which proves that the dielectric breakdown of the oxide layer was not yet attained. The thickness of the layer was slightly greater than that obtained at $100 \mathrm{~V}$ (Table 1, Fig. 5). The contact angle measured for the Nb-ANO-0.5-200 sample was smaller than that of the NbANO-0.5-100 sample (Table 1, Fig. 4). A greater hydrophilicity may stem from the higher roughness of the coating. Furthermore, it was reported by Godley et al. that the surface layer produced by soaking in alkali solution was composed from sodium niobate hydrogel [34]. Therefore, niobium species of the similar nature might be present onto the surface of the niobium anodised in alkali conditions, which in turn would have an effect on the hydrophilicity of the surface. The amount of silicon incorporated into the oxide layer was also found to be greater (Table 1, Fig. 5). The results suggest that the silicon content is higher in the outermost parts of the coating, which is consistent with the findings of other authors [46-49]. The coatings grown onto the samples anodised at voltages below the dielectric breakdown potential of the oxide layer were of a barrier-type and covered the entire surface of the niobium metal tightly.

The remainder of the niobium metal samples were subjected to the anodisation process at a voltage of $400 \mathrm{~V}$ (PEO) with varying concentrations of potassium silicate. The surface of the Nb-ANO-0.1-400 sample was covered with numerous pores with pore sizes of approximately $1 \mu \mathrm{m}$ (Fig. 3), and it was found to be relatively rough with an Ra equal to $0.82 \mu \mathrm{m}$ (Table 1, Fig. 4). The sample anodised in the bath that contained $0.5 \mathrm{~mol} \mathrm{dm}{ }^{-3}$ of $\mathrm{K}_{2} \mathrm{SiO}_{3}$ had a more rugged morphology (Fig. 3) and an increased roughness $(\mathrm{Ra}=1.85 \mu \mathrm{m}$,
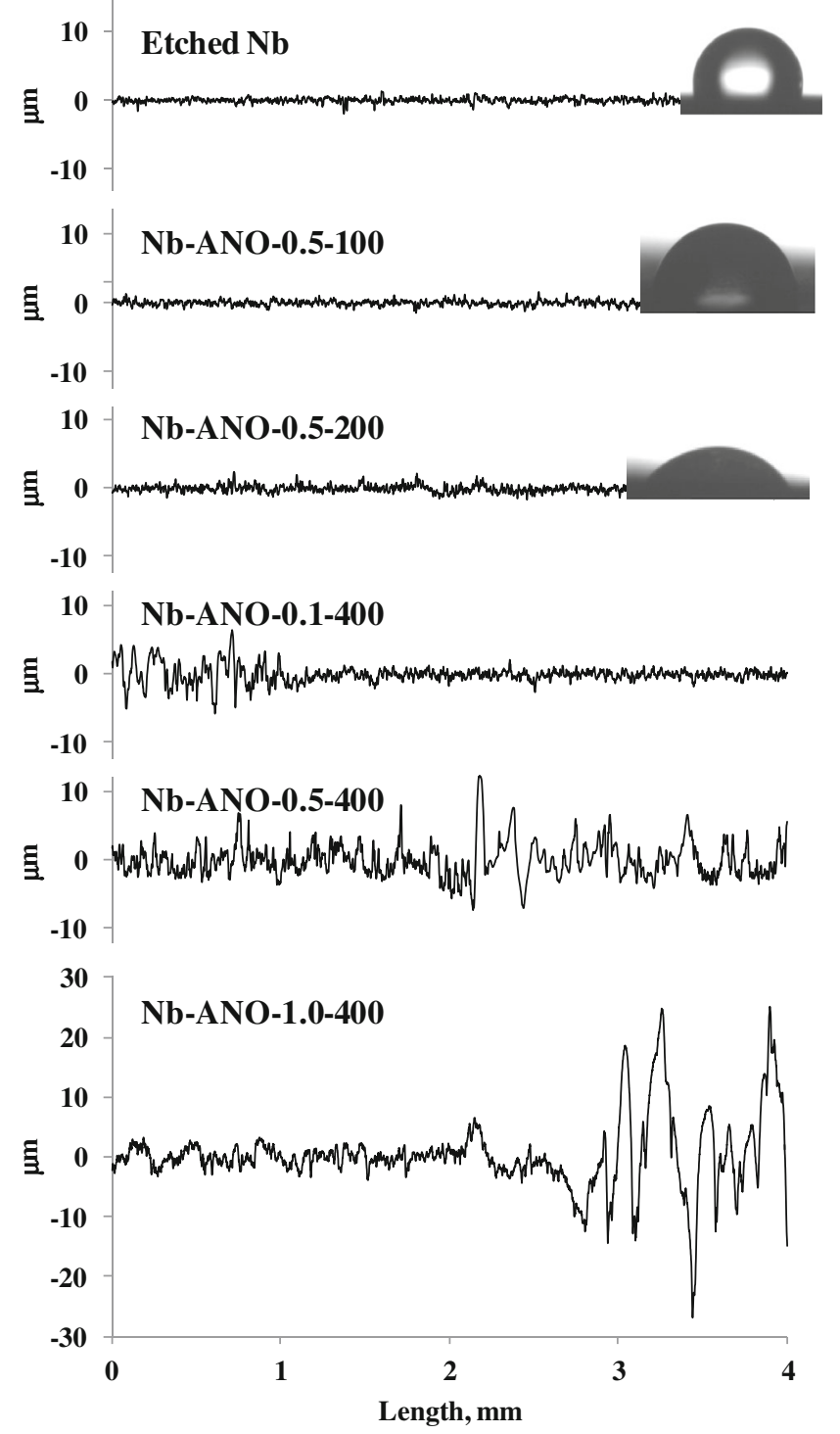

Fig. 4 The surface profiles of the etched niobium and the niobium that was anodised under various conditions (Nb-ANO- $x-y$ samples); inserts: contact angle measurement images 
Fig. 5 Cross-sectional images and EDX spectra of the niobium samples that were anodised at different voltages in solutions with different concentrations of $\mathrm{K}_{2} \mathrm{SiO}_{3}$
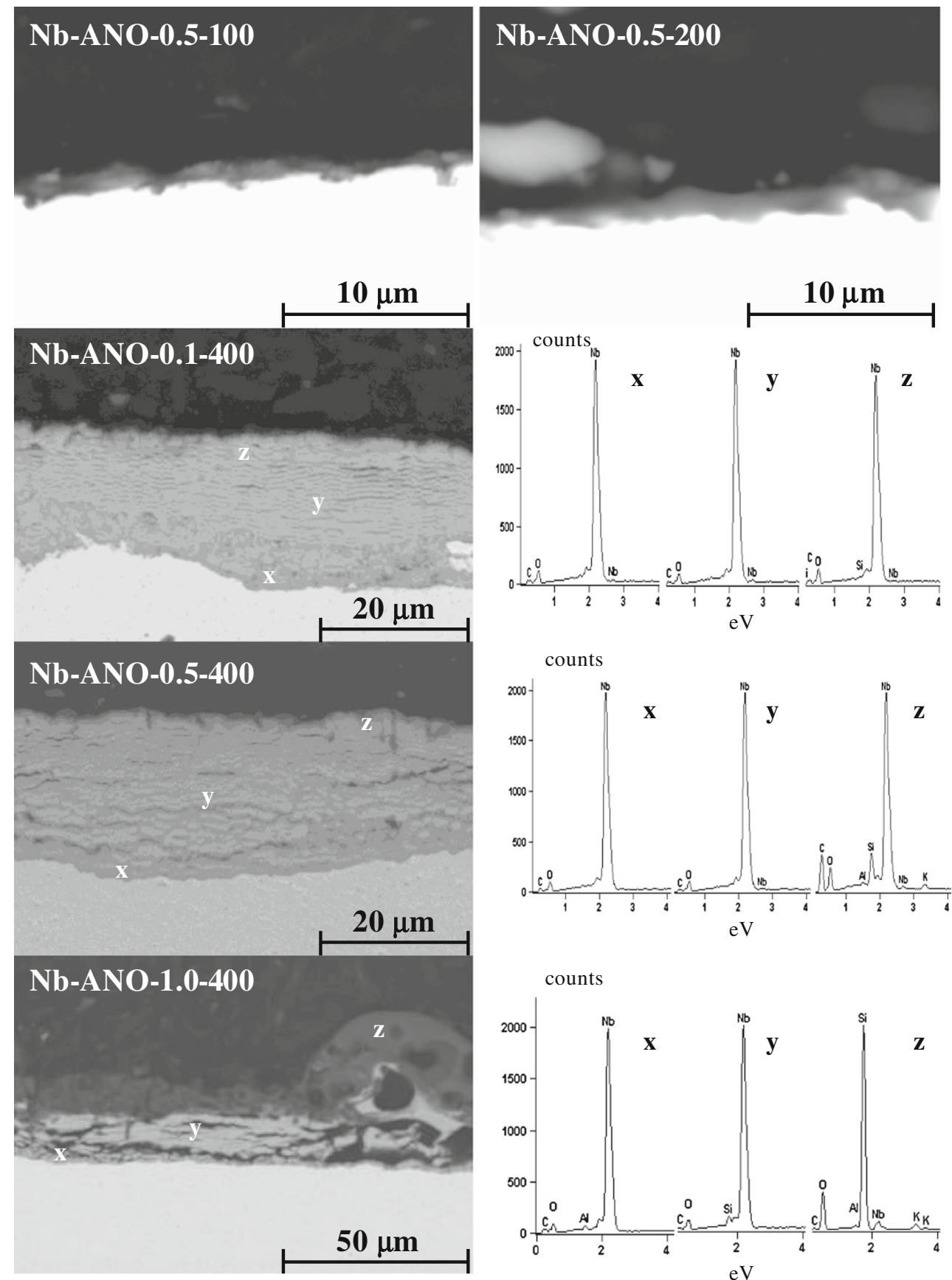

counts

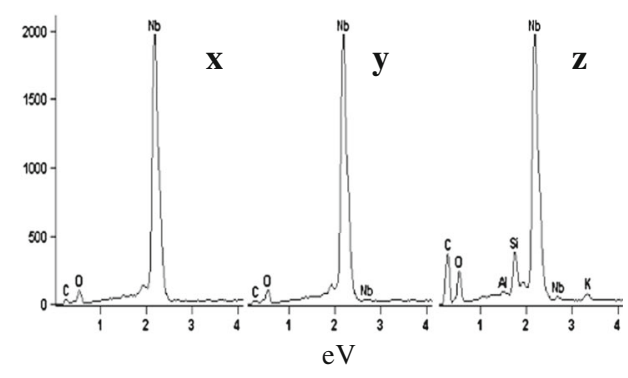

counts

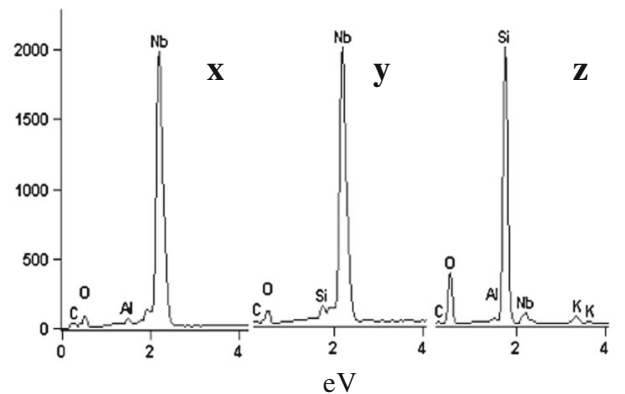

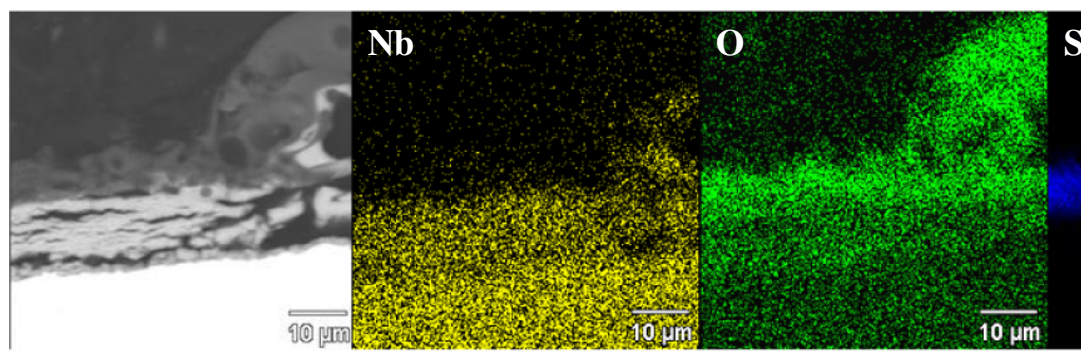

Si

K

Fig. 6 The EDX mapping of the oxide layer on the Nb-ANO-1.0-400 sample 
Fig. 7 TL-XRD patterns of the niobium samples (Nb-ANO- $x-y$ samples) that were anodised under various conditions
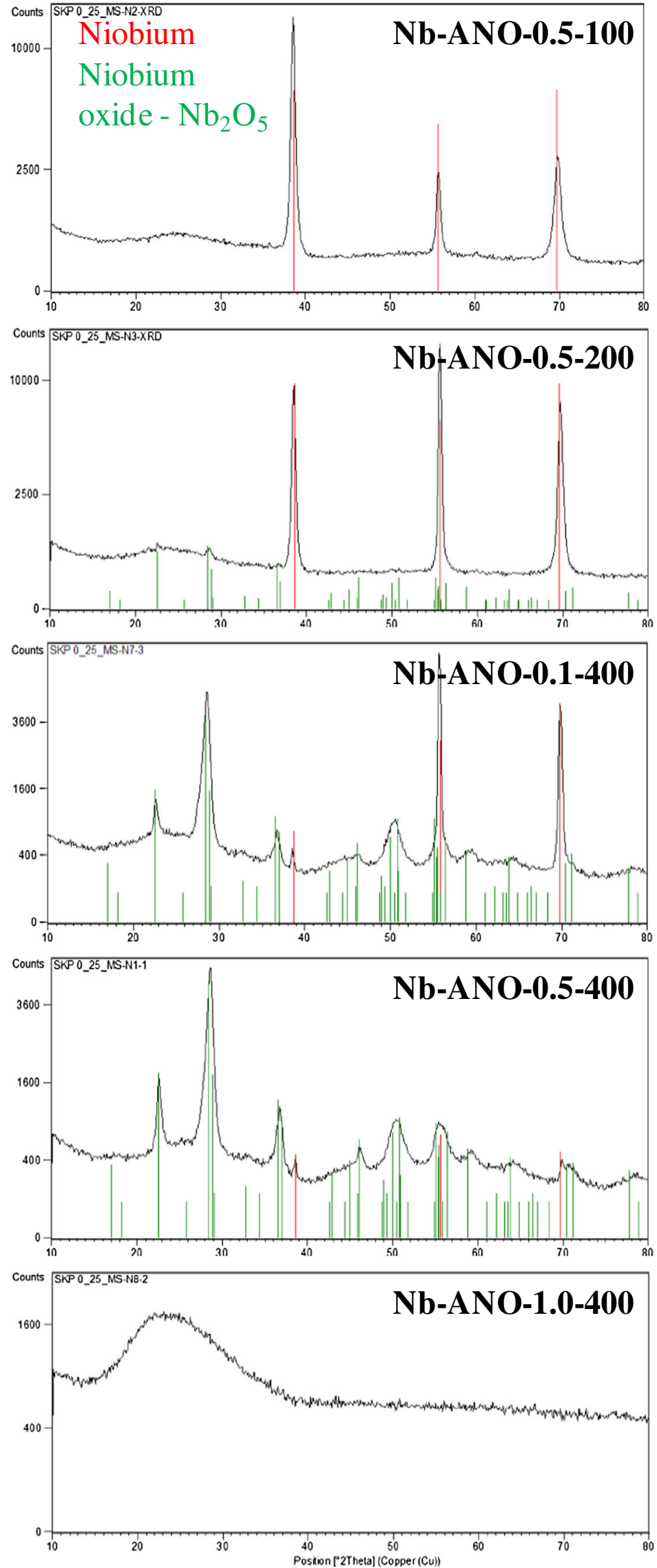
Table 1. Fig. 4) compared with the sample prepared in the more dilute solution. The size of the pores in the Nb-ANO$0.5-400$ sample was approximately $2 \mu \mathrm{m}$. Anodising of the niobium sample performed in the most concentrated solution of potassium silicate $\left(1.0 \mathrm{~mol} \mathrm{dm}^{-3}\right)$ led to the development of a highly rough surface (Fig. 4), with an $R a$ equal to $3.57 \mu \mathrm{m}$, which was dotted with a large number of pores of various sizes (from 5 to $40 \mu \mathrm{m}$ ) that appeared to be interconnected, which can be seen in Fig. 3. The measurements of the contact angle could not be performed for the samples anodised at a voltage of $400 \mathrm{~V}$ because of their extremely high hydrophilic character. The high porosity of the oxide layer grown on these samples is believed to be responsible for these findings. The thickness of the oxide layers grown in the anodising bath containing 0.1 and $0.5 \mathrm{~mol} \mathrm{dm}^{-3}$ was found to be very similar (Table 1, Fig. 5). However, the amount of silicon incorporated into the oxide layer was much higher in the case of the $\mathrm{Nb}$ ANO-0.5-400 sample than for the sample anodised in the solution that contained a lower concentration of potassium silicate (Table 1. Fig. 5). The amount of silicon was found to be higher in the outer parts of the oxide layer, compared to the inner parts, in the case of both of these samples. Apart from silicon, potassium, present in the electrolyte solution, was also found to be built into the oxide layer of the samples subjected to PEO (Fig. 5). The anodising of the niobium sample carried out in the most concentrated $\mathrm{K}_{2} \mathrm{SiO}_{3}$ solution and at a voltage of $400 \mathrm{~V}$ led to the growth of the thickest oxide layer of all of the niobium samples (Table 1, Fig. 5). The oxide layer was found to exhibit a number of inner closed pores and a distinct three-layered structure [50]. The innermost layer was of the barrier-type, similar to those grown on the samples anodised at voltages below the dielectric breakdown of the oxide. The intermediate layer was less compact, with a small amount of silicon incorporated from the electrolyte solution. The outermost, porous layer was found to contain a relatively large amount of silicon (Figs. 5 and 6) compared to the amount of niobium, which was also reported for PEO of zirconium alloy [46].

The XRD patterns obtained for the niobium samples anodised under various conditions are depicted in Fig. 7. Niobium pentoxide, $\mathrm{Nb}_{2} \mathrm{O}_{5}$, was detected in the XRD patterns for the niobium sample anodised under different conditions, which indicates that it is present in the crystalline form (Fig. 7). It was not detected in the sample anodised at a voltage of $100 \mathrm{~V}$, where only the peaks of the pure crystalline niobium were identified. Therefore, it can be stated that the anodic oxide film on this sample is composed of amorphous niobium oxide. Once the treatment voltage was raised to $200 \mathrm{~V}$, niobium pentoxide could be detected. The analysis of the XRD patterns of the samples that were subjected to anodisation performed at $400 \mathrm{~V}$ in various baths showed that the amount of the Nb-containing crystalline phases did not markedly changed with the $\mathrm{K}_{2} \mathrm{SiO}_{3}$ concentration. The XRD patterns of the niobium samples that have been subjected to PEO (under voltage of $400 \mathrm{~V}$ ) show a characteristic halo between $2 \theta$ equal to $15^{\circ}$ and $30^{\circ}$, which was also recognised by other researchers $[46,47,49,51]$ to be a signal of amorphous silica phase. This effect is the most pronounced in the case of the Nb-ANO-1.0-400 (Fig. 7), where the XRD pattern shows no distinct peaks in the crystalline phases, suggesting that a thick layer of amorphous silica covers the sample surface.

The XPS method showed that the surface layer of the analysed samples contains mainly silica/silicate deposits and that carbon species always adsorbed onto air-exposed specimens (Table 2). Traces of niobium were also found at the anodised surface. The electronic states of the elements in the approximately 12-nm thick surface layer (calculated as 3 inelastic mean free path, i.e. $3 \lambda$ ) were investigated using XPS. The results of the analysis of the high-resolution spectra are presented in Table 2. Taking into account that approximately $20 \%$ of carbon species are oxidised and the total amount of carbon at the surface layer is 21.3 at. $\%$, the
Table 2 Atomic concentrations of the elements and their chemical states at the surface of the Nb-ANO-0.5-400 sample as analysed by XPS

\begin{tabular}{llllllll}
\hline Excitation & $\begin{array}{l}\text { Atomic } \\
\text { concentration, } \\
\%\end{array}$ & Component & $\begin{array}{l}\mathrm{BE}, \\
\mathrm{eV}\end{array}$ & $\begin{array}{l}\text { FWHM, } \\
\mathrm{eV}\end{array}$ & $\begin{array}{l}\text { Comp. } \\
\text { ratio, } \%\end{array}$ & Assignation & Reference \\
\hline${\mathrm{Nb} 3 d_{5 / 2}}$ & 0.9 & $\mathrm{~A}$ & 207.7 & 2.5 & 100 & $\mathrm{Nb}^{5+}-\mathrm{O}$ & {$[51,52]$} \\
$\mathrm{Si} 2 p_{3 / 2}$ & 32.9 & $\mathrm{~A}$ & 100.3 & 2.0 & 4.2 & $\mathrm{Si}-\mathrm{O}-\mathrm{K}$ & {$[51-53]$} \\
& & $\mathrm{B}$ & 103.5 & 2.3 & 95.8 & $\mathrm{Si}-\mathrm{O}\left(\mathrm{SiO}_{2}\right)$ & {$[51,52]$} \\
$\mathrm{O} 1 s$ & 42.3 & $\mathrm{~A}$ & 530.6 & 2.2 & 6.9 & $\mathrm{O}-$ metal & {$[51,52]$} \\
& & $\mathrm{B}$ & 533.0 & 2.2 & 83.8 & $\mathrm{Si}-\mathrm{O}-\mathrm{Si}+\mathrm{H}_{2} \mathrm{O}$ & {$[51,52,54]$} \\
& & $\mathrm{C}$ & 534.2 & 2.1 & 9.3 & $\mathrm{Si}-\mathrm{OH}+\mathrm{O}-\mathrm{C}$ & {$[54]$} \\
$\mathrm{K} 2 p_{3 / 2}$ & 2.6 & $\mathrm{~A}$ & 294.0 & 2.4 & 100 & $\mathrm{~K}-\mathrm{O}-\mathrm{Si}$ & {$[52]$} \\
$\mathrm{C} 1 s$ & 21.3 & $\mathrm{~A}$ & 285.0 & 1.9 & 80.5 & $\mathrm{C}-\mathrm{C}$ & {$[51,52]$} \\
& & $\mathrm{B}$ & 286.4 & 1.9 & 15.3 & $\mathrm{C}-\mathrm{OH}$ & {$[51,52]$} \\
& & $\mathrm{C}$ & 288.3 & 2.5 & 4.2 & $\mathrm{COOH}$ & {$[51,52]$} \\
\hline
\end{tabular}


Fig. 8 The deconvoluted spectrum of $\mathrm{O} 1 s$ core excitation of the niobium that was anodised at $400 \mathrm{~V}$ in $0.5 \mathrm{~mol} \mathrm{dm}^{-3} \mathrm{~K}_{2} \mathrm{SiO}_{3}$ (Nb-ANO-0.5-400 sample)

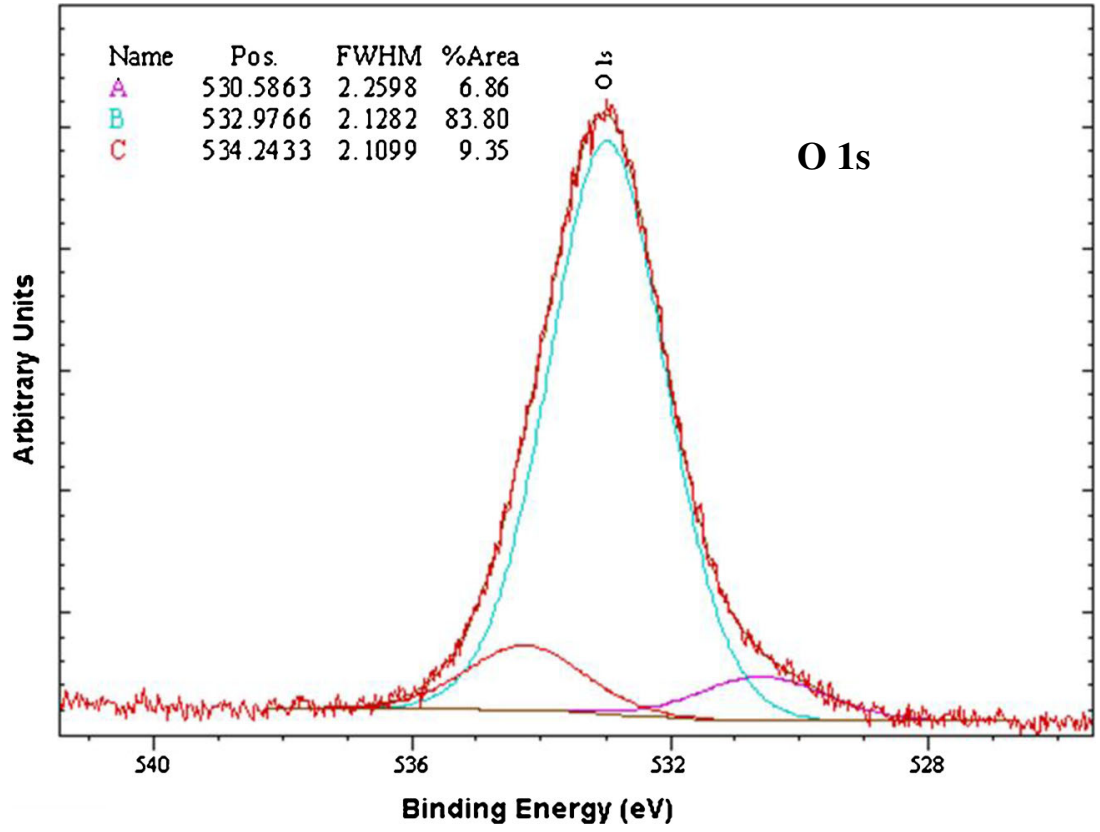

silicon-to-oxygen ratio is much lower than the stoichiometric $1: 2$ for $\mathrm{SiO}_{2}$. Additionally, the $\mathrm{Si} 2 p$ core excitation (Fig. 8) shows two components assigned to silicate $(\mathrm{A})$ and crystalline silica (B) where component B predominates [52-55]. In the XPS technique, most of the intensity, i.e. $63 \%$, originates from a depth of $1 \lambda$, leading to the conclusion that the surface is covered by stoichiometric $\mathrm{SiO}_{2}$, whereas the deeper parts show oxygen deficiency. This conclusion is also corroborated by analysis of the $O$ 1s spectrum (Fig. 9), where the most intense component can be assigned to siloxane type bonding (Si-O-Si) typical for silica [53, 55]. A small number of other oxygen species are attributed to the oxygen-metal bonding in silicates (component A), water (part of component B), and siloxanol and organic compounds (C). The presence of silicate species in the surface layer is confirmed by a maximum of the $\mathrm{K} 2 p_{3 / 2}$ core excitation at a $\mathrm{BE}$ of $294.0 \mathrm{eV}$, which is assigned to potassium silicate. Moreover, the analysis of the $\mathrm{K} / \mathrm{Si}$ (silicate) ratio shows that stoichiometric $\mathrm{K}_{2} \mathrm{SiO}_{3}$ is found at the analysed surface at $1.3 \mathrm{~mol} \%$. The analysed surface contained only a small amount of niobium $(\mathrm{V})$ species.

The open-circuit potential $\left(E_{\mathrm{OCP}}\right)$ values of the niobium samples were recorded in Ringer's physiological solution for a time of $1 \mathrm{~h}$. The results of these measurements are depicted in Fig. 10. The $E_{\mathrm{OCP}}$ increased once the niobium sample was
Fig. 9 The deconvoluted spectrum of $\operatorname{Si} 2 p$ core excitation of the niobium that was anodised at $400 \mathrm{~V}$ in $0.5 \mathrm{~mol} \mathrm{dm}^{-3} \mathrm{~K}_{2} \mathrm{SiO}_{3}$ (Nb-ANO-0.5-400 sample)

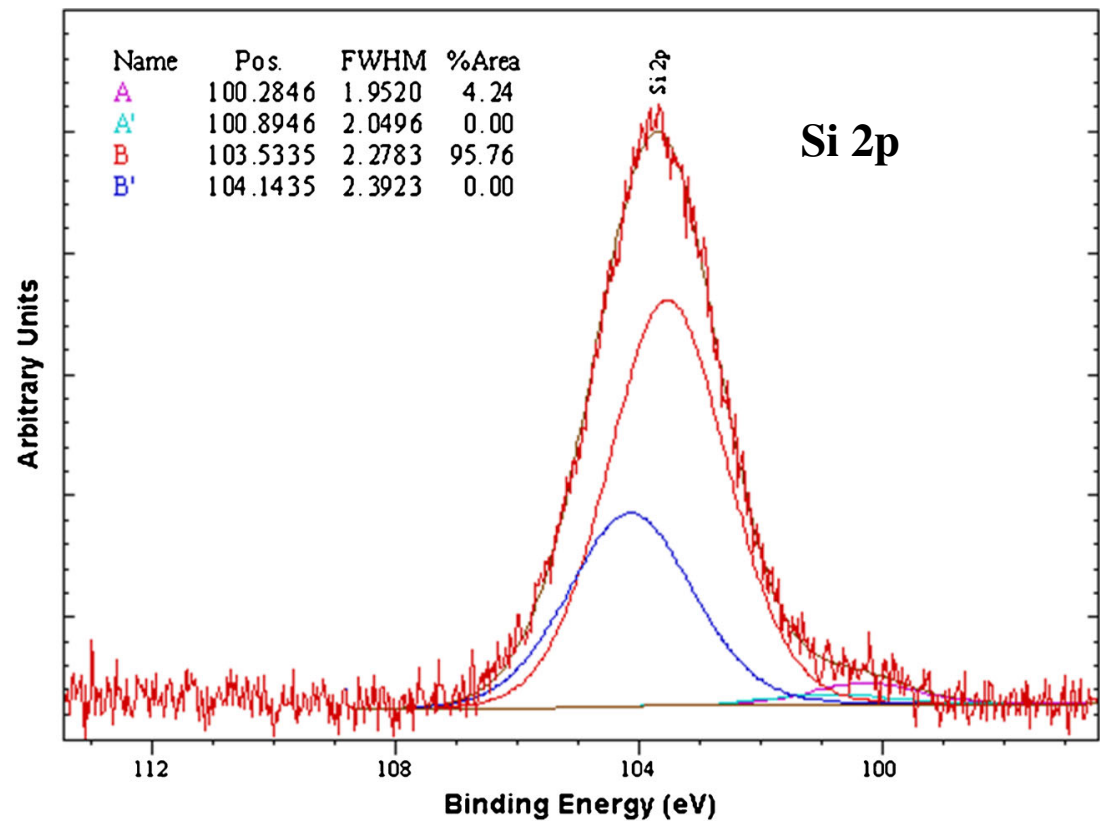


Fig. 10 The variation of the $E_{\mathrm{OCP}}$ with time in Ringer's solution for the etched niobium and the niobium that was anodised under various conditions (Nb-ANO- $x-y$ samples)

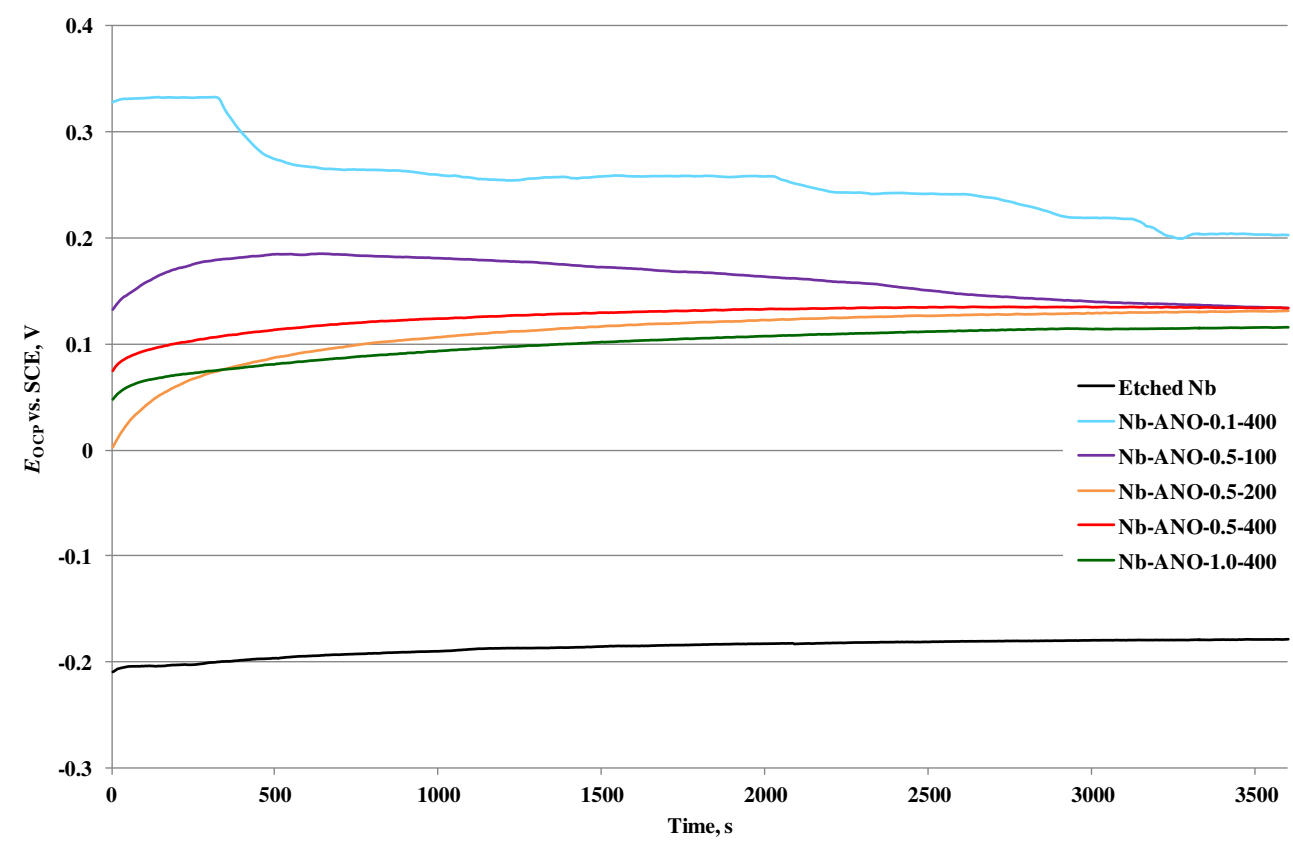

subjected to anodic oxidation when compared with the niobium sample that was only pretreated. Once the etched niobium sample was immersed in the Ringer's simulated body fluid, the open-circuit potential for that sample was observed to increase over time to its final value of $-178.5 \mathrm{mV}$ (Fig. 10). This trend is typical of valve (or refractory) metals [56]. The increase in potential is associated with sealing of the native oxide layer, indicating the surface activity of the metal. The niobium sample that was anodised at $100 \mathrm{~V}$ in a $0.5 \mathrm{~mol} \mathrm{dm}^{-3}$ $\mathrm{K}_{2} \mathrm{SiO}_{3}$ solution exhibited some surface activity at the beginning of the measurement (Fig. 10). However, after approximately $700 \mathrm{~s}$, the stability of the coating was lost, and the slow dissolution of the layer commenced. The $E_{\mathrm{OCP}}$ for this sample stabilised at the end of the experiment at a value of $133.6 \mathrm{mV}$. Such a significant shift towards the anodic direction indicates improved corrosion resistance of the niobium surface compared to the pretreated sample. The anodisation of the niobium sample at a voltage of $200 \mathrm{~V}$ yielded surface of the similar corrosion performance as the sample treated at $100 \mathrm{~V}$. The surface of this sample was observed to be more
Fig. 11 The polarisation curves recorded for the etched niobium and the niobium that was anodised under various conditions (Nb-ANO- $x-y$ samples)

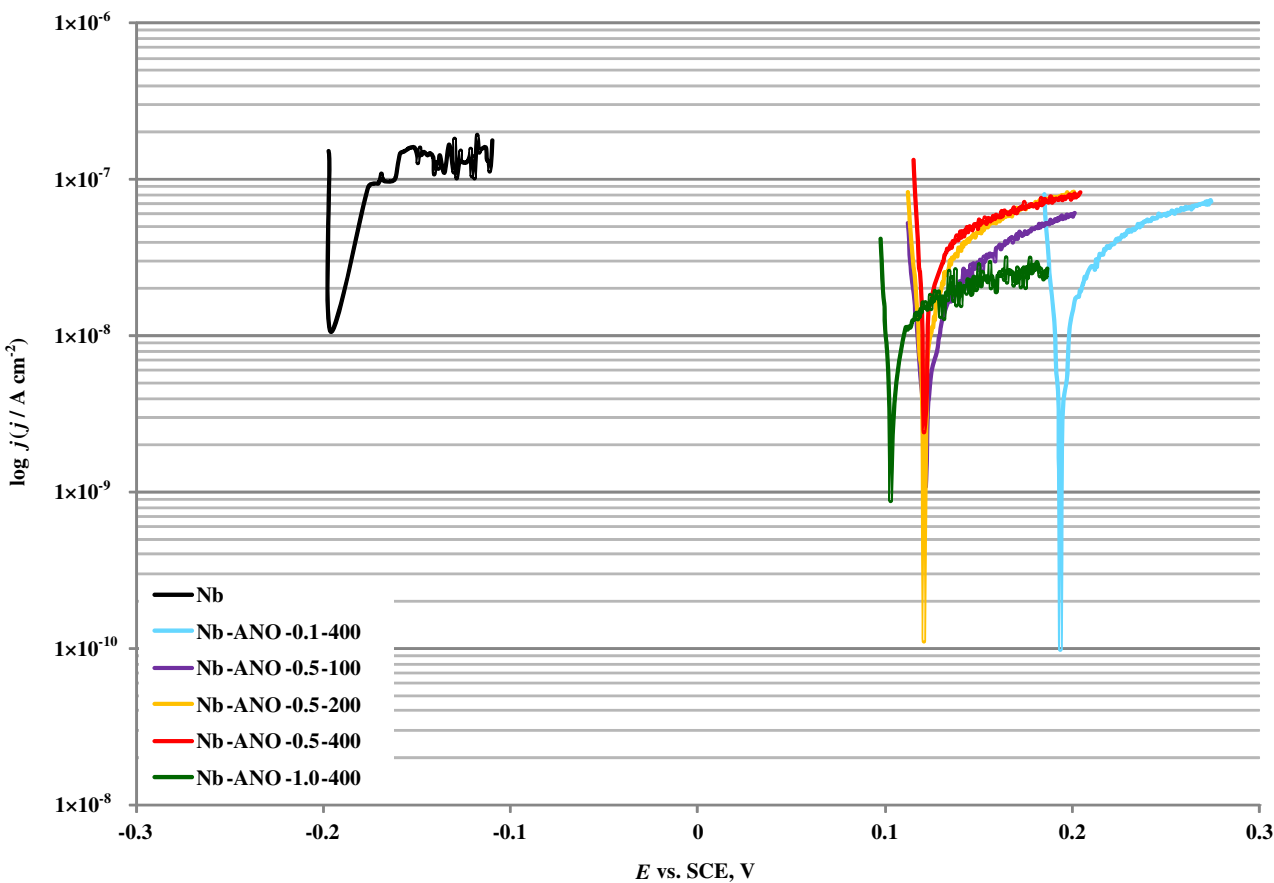


Table 3 The results of corrosion resistance investigations of the niobium samples in Ringer's solution

\begin{tabular}{llllll}
\hline Sample & $\mathrm{K}_{2} \mathrm{SiO}_{3}, \mathrm{~mol} \mathrm{dm}^{-3}$ & $U, \mathrm{~V}$ & $E_{\mathrm{CORR}}, \mathrm{mV}$ & $R_{\mathrm{p}}, \Omega \mathrm{cm}^{2}$ & $j_{\mathrm{CORR}}, \mathrm{A} \mathrm{cm}$ \\
\hline Etched Nb & - & - & -195.8 & $386 \times 10^{3}$ & $427.1 \times 10^{-9}$ \\
Nb-ANO-0.5-100 & 0.5 & 100 & 123.6 & $1.47 \times 10^{6}$ & $59.1 \times 10^{-9}$ \\
Nb-ANO-0.5-200 & & 200 & 121.6 & $1.54 \times 10^{6}$ & $56.5 \times 10^{-9}$ \\
Nb-ANO-0.5-400 & & 400 & 123.4 & $655 \times 10^{3}$ & $132.7 \times 10^{-9}$ \\
Nb-ANO-0.1-400 & 0.1 & 400 & 194.6 & $944 \times 10^{3}$ & $90.9 \times 10^{-9}$ \\
Nb-ANO-1.0-400 & 1.0 & & 104.0 & $1.23 \times 10^{6}$ & $70.7 \times 10^{-9}$ \\
\hline
\end{tabular}

active at the beginning of the measurement; however, the final value of the $E_{\mathrm{OCP}}$ for the Nb-ANO-0.5-200 sample was equal to $130.6 \mathrm{mV}$. A further increase in the processing voltage to $400 \mathrm{~V}$ (PEO) produced a surface with a similar degree of activity to the final open-circuit potential of $134 \mathrm{mV}$ (Fig. 10). The surface of the Nb-ANO-1.0-400 sample was observed to behave similarly under the experimental conditions (Fig. 10). The $E_{\mathrm{OCP}}$ value for this sample was determined to be equal to $115.9 \mathrm{mV}$. This value is somewhat more negative than the values obtained for the other oxidised niobium samples, which can be associated with non-homogeneity of the treated surface and with large pores that can be easily penetrated by chloride ions. The niobium sample, which was anodised at $400 \mathrm{~V}$ in a solution that contained $0.1 \mathrm{~mol} \mathrm{dm}^{-3}$ of $\mathrm{K}_{2} \mathrm{SiO}_{3}$, attained the highest value of the open-circuit potential $(203.2 \mathrm{mV}$ ) out of all the analysed niobium samples (Fig. 10). However, the dissolution of the oxide layer commenced after approximately $400 \mathrm{~s}$ with the $E_{\mathrm{OCP}}$ decreasing as time elapsed. Such a significant shift in the open-circuit potential compared with the etched niobium sample can be attributed to the surface morphology of the sample (Figs. 3 and 5). The oxide layer of this sample was relatively thick and compact, which did not permit penetration to the metal surface. Nevertheless, the oxide was not stable in the SBF, which is suggested by the decreasing trend of the $E_{\mathrm{OCP}}=f(t)$ curve.

The linear polarisation method was applied for the determination of the corrosion parameters $\left(E_{\mathrm{CORR}}, j_{\mathrm{CORR}}\right.$, and $\left.R_{\mathrm{p}}\right)$ of the niobium samples. The data were extracted from the polarisation curves recorded for those samples (Fig. 11) in Ringer's SBF, and the results are summarised in Table 3. The corrosion potential of the etched niobium sample was determined to be $-195.8 \mathrm{mV}$, which is lower than its open-circuit potential, as could have been expected because the potential scan began at a cathodic potential and was swept in the anodic direction. This scan profile resulted in a partial reduction of the oxide film, and therefore, a decreased corrosion potential value [22]. The corrosion current density and polarisation resistance of the etched niobium sample were found to be equal to $427.1 \mathrm{nA} \mathrm{cm}{ }^{-2}$ and $386 \mathrm{k} \Omega \mathrm{cm}^{2}$, respectively. The anodisation of niobium at a voltage below the breakdown potential of the oxide layer, that is, 100 and $200 \mathrm{~V}$, resulted in a significant shift in the corrosion potential towards the
Fig. 12 The cyclic polarisation curves recorded for the etched niobium and the niobium that was anodised under various conditions (Nb-ANO- $x-y$ samples)

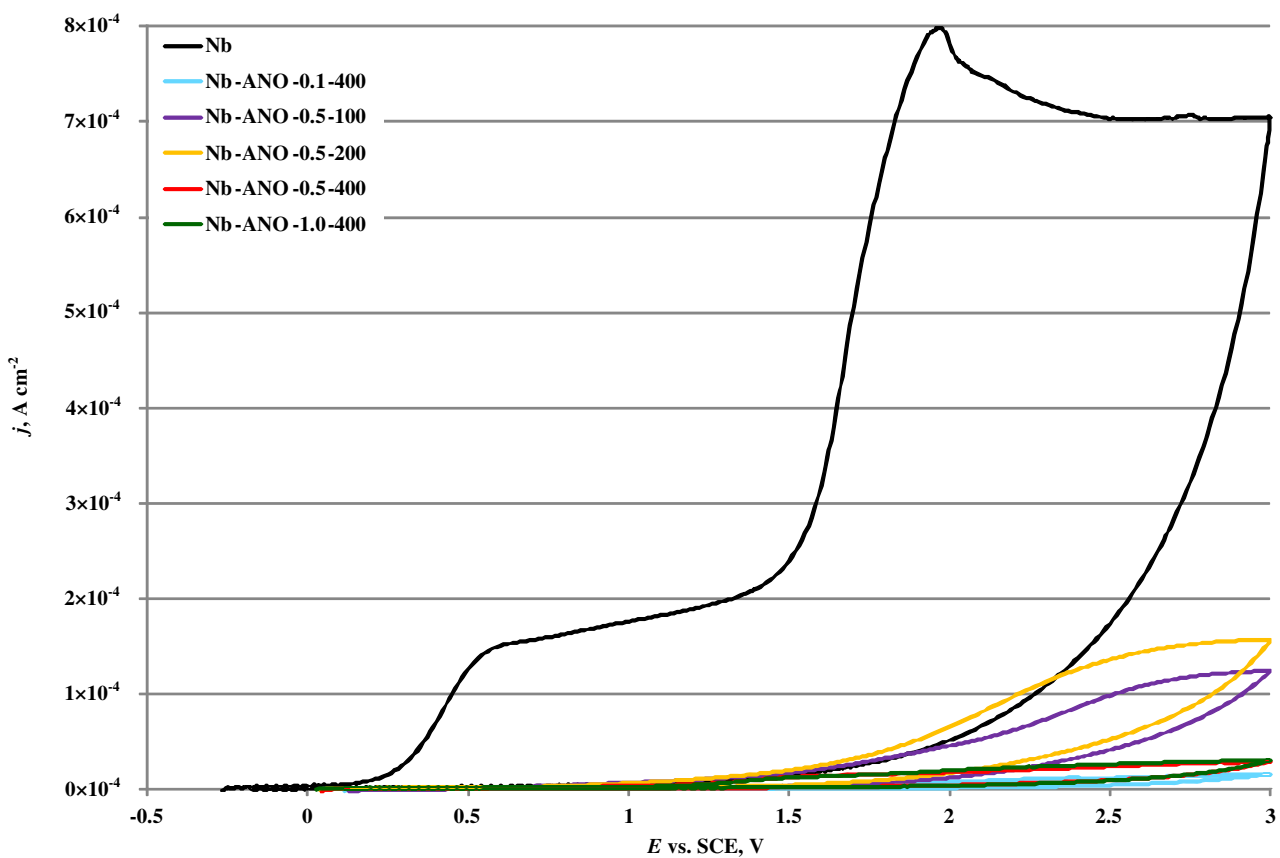


noble metal side of 123.6 and $121.6 \mathrm{mV}$, respectively. The current density for those samples decreased to 59.1 and $56.5 \mathrm{nA} \mathrm{cm}^{-2}$, respectively, compared with the pure niobium, while their polarisation resistance was raised to 1.47 and $1.54 \mathrm{M} \Omega \mathrm{cm}^{2}$, respectively. The anodic oxidation of the niobium samples under PEO conditions in solutions of 0.1 , 0.5 , and $1.0 \mathrm{~mol} \mathrm{dm}^{-3}$ led to an anodic shift in their corrosion potential to $194.6,123.4$, and $104.0 \mathrm{mV}$, respectively. This finding is associated with the surface morphology of the sample (Figs. 3 and 5). The highly porous and loose surface of the Nb-ANO-0.5-400 and Nb-ANO-1.0-400 samples provides worse corrosion protection than the more compact and tightly adhering oxide layer grown on the Nb-ANO-0.1-400 surface. The results from our previous studies on the anodisation of tantalum [42] and zirconium [44] follow a similar trend.

The results of the cyclic polarisation investigations performed on the niobium samples are presented in Fig. 12. The shape of the polarisation curve recorded for the etched niobium sample is typical of valve metals [23, 57-59]. The anodic scan reveals that the surface passivation phenomenon commenced at approximately $0.2 \mathrm{~V}$, where $\mathrm{NbO}$ and $\mathrm{NbO}_{2}$ are oxidised to $\mathrm{Nb}_{2} \mathrm{O}_{5}$ [59], with a characteristic plateau, and at a potential of $1.7 \mathrm{~V}$, the evolution of oxygen took place (Fig. 12). No transpassivation was observed for this sample, which indicates that no pitting corrosion occurred during the scan. During the reverse scan, the current quickly dropped to negligible values, which signifies that the oxide grown during the anodic scan had not undergone subsequent reduction. The curves that were recorded for the niobium samples, which were subjected to anodic oxidation in potassium silicate solutions, reached much lower maximum current values than the etched niobium sample, which is attributed to the existence of the relatively thick oxide layers that limit the flow of current through the sample. No transpassivation region could be identified for the anodised samples, which proves that the electrochemical modification of the surface layer led to a notable improvement in the corrosion resistance when compared with the pure niobium surface. The lowest current values were recorded for the sample anodised in a $0.1 \mathrm{~mol} \mathrm{dm}^{-3} \mathrm{~K}_{2} \mathrm{SiO}_{3}$ solution at a voltage of $400 \mathrm{~V}$, whereas the highest current values were observed for the Nb-ANO0.5-200 sample.

\section{Conclusions}

The effects of anodic oxidation on the characteristics of the oxide coatings generated on pure niobium at various process voltages in baths that contained different amounts of potassium silicate were investigated in this work. This method of surface modification enables the incorporation of silicon into the oxide coatings. Relatively thin, uniform and barrier-type coatings slightly enriched in silicon are obtained on niobium when the process voltage is below the breakdown potential of the oxide layer. When the plasma electrolytic oxidation conditions are attained, the resulting coatings are thick, porous and rough. Crystalline $\mathrm{Nb}_{2} \mathrm{O}_{5}$ and $\mathrm{Nb}$ were identified in those oxide layers. The coatings on the PEO treated niobium samples exhibited a three-layered structure, with an innermost compact barrier layer, an intermediate more loosely structured layer and an outermost highly porous layer composed mainly from amorphous silica. The amount of silicon incorporated into the coatings was higher at higher voltages and higher concentrations of potassium silicate in the anodising bath. The electrolyte components were the most abundant in the outer layers of the oxide coatings on the niobium samples treated at $400 \mathrm{~V}$. The modification improved the resistance to corrosion in Ringer's physiological solution of all the treated niobium samples compared to that of pure niobium, regardless of the imposed process conditions, with the best performance obtained for the niobium sample anodised at $400 \mathrm{~V}$ in a $0.1 \mathrm{~mol} \mathrm{dm}^{-3}$ potassium silicate solution. Although the present results are promising, biocompatibility experiments and studies of the mechanical properties of these oxide layers must be conducted to ascertain their usefulness in the biomaterials field.

Acknowledgements This work was supported by the Polish Ministry of Science and Education under research project no. IP 2011049471.

Open Access This article is distributed under the terms of the Creative Commons Attribution License which permits any use, distribution, and reproduction in any medium, provided the original author(s) and the source are credited.

\section{References}

1. Ratner BD, Hoffman AS, Schoen FJ, Lemons JE (2004) Biomaterials science: an introduction to materials in medicine, 2nd edn. Elsevier Academic Press, San Diego, pp 1-9

2. Marciniak J (2002) Biomateriały, Wydawnictwo Politechniki Śląskiej, Gliwice (in Polish), pp. 68-89

3. Niinomi M (2002) Metall Mater Trans A 33:477-486

4. Black J (1988) J Bone Jt Surg Br 70:517-520

5. Hanawa T (1999) Mater Sci Eng A 267:260-266

6. Balamurugan A, Rajeswari S, Balossier G, Rebelo AHS, Ferreira JMF (2008) Mater Corros 59:855-869

7. Long M, Rack HJ (1998) Biomaterials 19:1621-1639

8. Geetha M, Singh AK, Asokamani R, Gogia AK (2009) Prog Mater Sci 54:397-425

9. Rogers SD, Howie DW, Graves SE, Pearcy MJ, Haynes DR (1997) J Bone Jt Surg Br 79:311-315

10. Okazaki Y, Sethumadhavan R, Ito Y, Tateishi T (1998) Biomaterials 19:1197-1215

11. López MF, Gutiérrez A, Jiménez JA (2002) Electrochim Acta 47: 1359-1364

12. Pennekamp PH, Gessmann J, Diedrich O, Burian B, Wimmer MA, Frauchiger VM, Kraft CN (2006) J Orthop Res 24:531-540 
13. Crapper McLachlan DR, Lukiw WJ, Kruck TPA (1990) Environ Geochem Health 12:103-114

14. Landsberg JP, McDonald B, Watt F (1992) Nature 360:65-68

15. Matsuno H, Yokoyama A, Watari F, Uo M, Kawasaki T (2001) Biomaterials 22:1253-1262

16. Krząkała A, Służalska K, Dercz G, Maciej A, Kazek A, Szade J, Winiarski A, Dudek M, Michalska J, Tylko G, Osyczka AM, Simka W (2013) Electrochim Acta 104:425-438

17. Eisenbarth E, Velten D, Müller M, Thull R, Breme J (2004) Biomaterials 25:5705-5713

18. Assis SL, Rogero SO, Antunes RA, Padilha AF, Costa I (2005) J Biomed Mater Res B 79:109-116

19. Okazaki Y, Ito Y, Kyo K, Tateishi T (1996) Mater Sci Eng A 213: 138-147

20. Simka W, Socha RP, Dercz G, Michalska J, Maciej A, Krząkała A (2013) Appl Surf Sci 279:317-323

21. Karayan AI, Park SW, Lee KM (2008) Mater Lett 62:1843-1845

22. Assis SL, Wolynec S, Costa I (2006) Electrochim Acta 51:1815-1819

23. Oliveira NTC, Ferreira EA, Duarte LT, Biaggio SR, Rocha-Filho RC, Bocchi N (2006) Electrochim Acta 51:2068-2075

24. Gao Y, Gao B, Wang R, Wu J, Zhang LJ, Hao YL, Tao XJ (2009) Appl Surf Sci 255:5009-5015

25. Leoni A, Apachitei I, Riemslag AC, Fratila-Apachitei LE, Duszczyk J (2011) Mater Sci Eng C 31:1779-1783

26. Niinomi M (2003) Biomaterials 24:2673-2683

27. Biason Gomes MA, Onofre S, Juanto S, Bulhões LOS (1991) J Appl Electrochem 21:1023-1026

28. Ramírez G, Rodil SE, Arzate H, Muhl S, Olaya JJ (2011) Appl Surf Sci 257:2555-2559

29. Liu X, Chu PK, Ding C (2004) Mater Sci Eng R 47:49-121

30. Ou SF, Lin CS, Pan YN (2011) Surf Coat Technol 205:2899-2906

31. Aronsson BO, Lausmaa J, Kasemo B (1997) J Biomed Mater Res A 35:49-73

32. Wu S, Liu X, Yeung KWK, Guo H, Li P, Hu T, Chung CY, Chu PK (2013) Surf Coat Technol 233:13-26

33. Rosenberg R, Starosvetsky D, Gotman I (2003) J Mater Sci Lett 22: 29-32

34. Godley R, Starosvetsky D, Gotman I (2003) J Mater Sci-Mater M 15: 1073-1077

35. Eisenbarth E, Velten D, Müller M, Thull R, Breme J (2006) J Biomed Mater Res A 79:166-175

36. Yerokhin AL, Nie X, Leyland A, Matthews A, Dowey SJ (1999) Surf Coat Technol 122:73-93
37. Snizhko LO, Yerokhin AL, Pilkington A, Gurevina NL, Misnyankin DO, Leyland A, Matthews A (2004) Electrochim Acta 49:20852095

38. Pietak AM, Reid JW, Stott MJ, Sayer M (2007) Biomaterials 28: 4023-4032

39. Ning CQ, Mehta J, El-Ghannam A (2005) J Mater Sci-Mater M 16: 355-360

40. Dorozhkin SV (2007) J Am Ceram Soc 90:244-249

41. Kovács K, Kiss G, Stenzel M, Zillgen H (2003) J Electrochem Soc 150:B361-B366

42. Sowa M, Kazek-Kęsik A, Socha RP, Dercz G, Michalska J, Simka W (2013) Electrochim Acta. doi: 10.1016/j.electacta.2013.10.047

43. Petković M, Stojadinović S, Vasilić R (2011) Zeković Lj. Appl Surf Sci 257:10590-10594

44. Simka W, Sowa M, Socha RP, Maciej A, Michalska J (2013) Electrochim Acta 104:518-525

45. Simka W (2011) Electrochim Acta 56:9831-9837

46. Cheng Y, Matykina E, Skeldon P, Thompson GE (2011) Electrochim Acta 56:8467-8476

47. Cheng Y, Matykina E, Arrabal R, Skeldon P, Thompson GE (2012) Surf Coat Technol 206:3230-3239

48. Duan H, Yan C, Wang F (2007) Electrochim Acta 52:5002-5009

49. Monfort F, Berkani A, Matykina E, Skeldon P, Thompson GE, Habazaki H, Shimizu K (2007) Corros Sci 49:672-693

50. Cheng Y, Wu F, Matykina E, Skeldon P, Thompson GE (2012) Corros Sci 59:307-315

51. Krupa D, Baszkiewicz J, Zdunek J, Smolik J, Słomka Z, Sobczak JW (2010) Surf Coat Technol 205:1743-1749

52. Chastain J, Moulder JF, Stickle WF, Sobol PE, Bomben L (1992) Handbook of X-ray photoelectron spectroscopy, 2nd edn. PerkinElmer Corporation, Eden Prairie

53. NIST X-ray Photoelectron Spectroscopy Database; http://srdata.nist. gov/xps/

54. Sawyer R, Nesbitt HW, Secco RA (2012) J Non-Cryst Solids 358: 290-302

55. Simonsen ME, Sønderby C, Li Z, Søgaard EG (2009) J Mater Sci 44: 2079-2088

56. Guo WY, Sun J, Wu JS (2009) Mater Chem Phys 113:816-820

57. Sulyma CN, Roy D (2010) Corros Sci 52:3086-3098

58. Oliveira NTC, Guastaldi AC (2008) Corros Sci 50:938-945

59. Krząkała A, Służalska K, Widziołek M, Szade J, Winiarski A, Dercz G, Kazek A, Tylko G, Michalska J, Iwaniak A, Osyczka AM, Simka W (2013) Electrochim Acta 104:407-424 